\title{
PENGARUH BRAND IMAGE TERHADAP KEPUASAN DAN LOYALITAS PELANGGAN PADA PT. BRAND X DI JAKARTA
}

\author{
Alex Santana \\ Program Studi Magister Manajemen Universitas Tarumanagara \\ a_santana85@yahoo.com \\ Keni \\ Program Studi Magister Manajemen Universitas Tarumanagara \\ Masuk : 06-12-2019, revisi : 18-12-2019 diterima untuk diterbitkan : 19-12-2019
}

\begin{abstract}
The aim of this study are : First, to explore the effect of brand image on customer loyalty. Second, to explore the effect of brand image on customer satisfaction. Third, to explore the effect of customer satisfaction towards customer loyalty. Fourth, to find out if customer satisfaction can mediate brand image towards customer loyalty. The method of data collection is convenience sampling. The samples of this research are collected from 135 respondens, who are the customers of Brand $\mathrm{x}$ in Jakarta. The technique of data analysis used in this study was regression analysis and mediating test to find put the hypotheses. The results are : (a) the effect between brand image have a significant and positive impact toward customer loyalty; (b) the effect between brand image have a significant and positive impact toward customer satisfaction; (c) customer satisfaction has a positive impact on customer loyalty; (d) customer satisfaction will mediate the effect of brand image towards customer loyalty.
\end{abstract}

Abstrak : Tujuan dari penelitian ini adalah : pertama, untuk untuk menguji efek dari brand image terhadap loyalitas pelanggan. Kedua, untuk menguji efek dari brand image terhadap kepuasan pelanggan. Ketiga, untuk menguji efek dari kepuasan pelanggan terhadap loyalitas pelanggan. Keempat, untuk mengetahui apakah kepuasan pelanggan dapat memediasi brand image terhadap loyalitas pelanggan. Metode dari pengambilan data adalah convenience sampling. Sampel merupakan pelanggan brand X di Jakarta. Sampel dari penelitian ini adalah 135 responden. Teknik dari data analisis penelitian ini adalah analisis regresi sederhana dan analisis mediasi untuk menentukan hipotesis. Hasilnya adalah : Hasilnya adalah (a) brand image mempunyai pengaruh positif terhadap loyalitas pelanggan. (b) brand image mempunyai pengaruh positif terhadap kepuasan pelanggan (c) kepuasan pelanggan mempunyai pengaruh positif terhadap loyalitas pelanggan (d) kepuasan pelanggan dapat memediasi pengaruh brand image terhadap loyalitas pelanggan

Keywords : Brand Image; Kepuasan Pelanggan; Loyalitas Pelanggan

\section{PENDAHULUAN}

Pertumbuhan perekonomian dunia sekarang ini semakin bergeser ke Asia Pasifik, terbukti dengan dikuasainya populasi dunia, $60 \%$ perkenomian dan hampir $50 \%$ perdagangan dunia (Yang Yi, 2019). Pertumbuhan ini seiiring dengan bangkitnya populasi generasi milenial di beberapa negara di Asia, antara lain Indonesia, Malaysia, Singapura, Timor Leste, Vietnam dan Filipina.

Keberhasilan suatu bisnis tidak dapat dipisahkan dari pelanggan yang menjadi target utama dari sumber pendapatan bagi perusahaan. Menurut Tjiptono (2005), loyalitas pelanggan adalah situasi ideal yang paling diharapkan dari para pemasar, dimana konsumen bersifat positif terhadap produk / produsen dan disertai pola pembelian ulang yang konsisten. 
Loyalitas pelanggan dipengaruhi oleh brand image. Sejalan dengan Upamanyu dan Sankpal (2011) menunjukkan ada hubungan yang kuat antara brand image dan niat loyalitas. Menurut Kotler dan Keller (2015: 768) adalah "brand image is the perceptions and beliefs held by consumers, as reflected is the associations held in customer memory". Menurut Kotler dan Keller (2016: 152) menjelaskan loyalitas bahwa "A deeply held commitment to rebuy or repatronize a preferred product or service in the future despite situational influences and marketing efforts having the potential to cause switching behavior". Lebih lanjut Menurut Kotler dan Keller (2016: 150) mendefiniskan customer satisfaction sebagai "a person's feelings of pleasure or disappointment that result from comparing a product or service's perceived performance (or outcomes) to ecpectations." Hal ini diperkuat dengan penelitian yang dikemukakan oleh Ghafoor, Iqbal dan Murtaza (2012) bahwa kepuasan pelanggan dan brand image keduanya memiliki pengaruh yang positif terhadap loyalitas pelanggan,

Tujuan dari penelitian ini adalah untuk mengetahui: (1) pengaruh brand image terhadap loyalitas pelanggan; (2) pengaruh brand image terhadap kepuasan pelanggan; (3) pengaruh kepuasan pelanggan terhadap loyalitas pelanggan; (4) apakah kepuasan pelanggan dapat menjadi mediasi pengaruh brand image terhadap loyalitas pelanggan. Hasil penelitian ini diharapkan dapat memberikan memberikan informasi kepada Lady Americana dalam pengambilan keputusan untuk mempertahankan loyalitas pelanggan dengan penggunaan faktor brand image dan kepuasan pelanggan.

\section{LANDASAN TEORI}

Definisi brand image menurut Kotler dan Keller (2015: 768) adalah "brand image is the perceptions and beliefs held by consumers, as reflected is the associations held in customer memory". Brand image adalah persepsi dan kepercayaan konsumen, sebagaimana tercermin dalam asosiasi di ingatan konsumen.

Menurut Menurut Heiller (2002: 1765) menyatakan "Customer satisfaction is the degree of overall pleasure or contentment felt by the customer, resulting from the abiity of the service to fullfill the customer's desires, expectations and needs in relation to the service". Kepuasan pelanggan adalah perasaan konsumen secara keseluruhan, yang dihasilkan dari pelayanan yang baik untuk memenuhi keinginan, harapan dan kebutuhan konsumen.

Menurut Menurut Kotler dan Keller (2016: 152) "A deeply held commitment to rebuy or repatronize a preferred product or service in the future despite situational influences and marketing efforts having the potential to cause switching behavior " Loyalitas pelanggan adalah komitmen untuk membeli kembali suatu produk atau jasa di masa depan meskipun situasi dan bentuk penawaran yang diberikan telah berubah akibat peubahan perilaku konsumen.

Pengaruh brand image terhadap Loyalitas Pelanggan. Upamanyu dan Sankpal (2011) menunjukkan ada hubungan yang kuat antara brand image dan niat loyalitas. Ukuran brand image terdiri dari peningkatan fungsional, sosial, simbolik, pengalaman dan penampilan yang menyiratkan bahwa pemasar harus fokus pada manfaat brand image untuk mencapai loyalitas pelanggan. Berdasarkan penjelasan diatas, maka hipotesis penelitian adalah sebagai berikut : H1 : Terdapat pengaruh positif brand image terhadap loyalitas pelanggan.

Pengaruh brand image terhadap Kepuasan Pelanggan. Menurut penelitian yang dilakukan oleh Stan, Caemmere dan Jallet (2013) menyatakan bahwa terdapat pengaruh dari brand image terhadap customer satisfaction. Pelanggan yang mengkonsumsi produk, baik barang maupun jasa dengan citra merek yang baik akan mendapatkan kepuasan yang lebih. Berdasarkan paparan diatas, maka hipotesis penelitian adalah sebagai berikut :

$\mathrm{H} 2$ : Terdapat pengaruh positif brand image terhadap kepuasan pelanggan. 
Pengaruh Kepuasan Pelanggan terhadap Loyalitas Pelanggan. Penelitian yang dilakukan Gronholdt, Martensen dan Kristensen (2000) menyatakan bahwa hubungan antara kepuasan dan loyalitas pelanggan sangat penting. Bhattacharya et al. (2011) yang dalam penelitianya menyatakan customer satisfaction memiliki pengaruh yang signifikan positif terhadap customer loyalty. Berdasarkan paparan diatas, maka hipotesis penelitian adalah sebagai berikut :

H3 : Terdapat pengaruh positif antara kepuasan pelanggan terhadap loyalitas pelanggan.

Kepuasan Pelanggan Memediasi Brand Image terhadap Loyalitas Pelanggan. Dalam penelitiannya, Ghafoor, Iqbal dan Murtaza (2012) menyatakan bahwa kepuasan pelanggan dan brand image keduanya memiliki pengaruh yang positif terhadap loyalitas pelanggan, konsumen yang loyal terhadap suatu brand didukung oleh kepuasan melalui pelayanan yang baik dan komunikasi serta pengembangan dari suatu brand dengan positioning yang tepat. Berdasarkan paparan diatas, maka hipotesis penelitian adalah sebagai berikut :

H4 : Kepuasan pelanggan dapat memediasi pengaruh brand image secara positif terhadap loyalitas pelanggan pada PT. Lady Americana Indonesia di Jakarta.

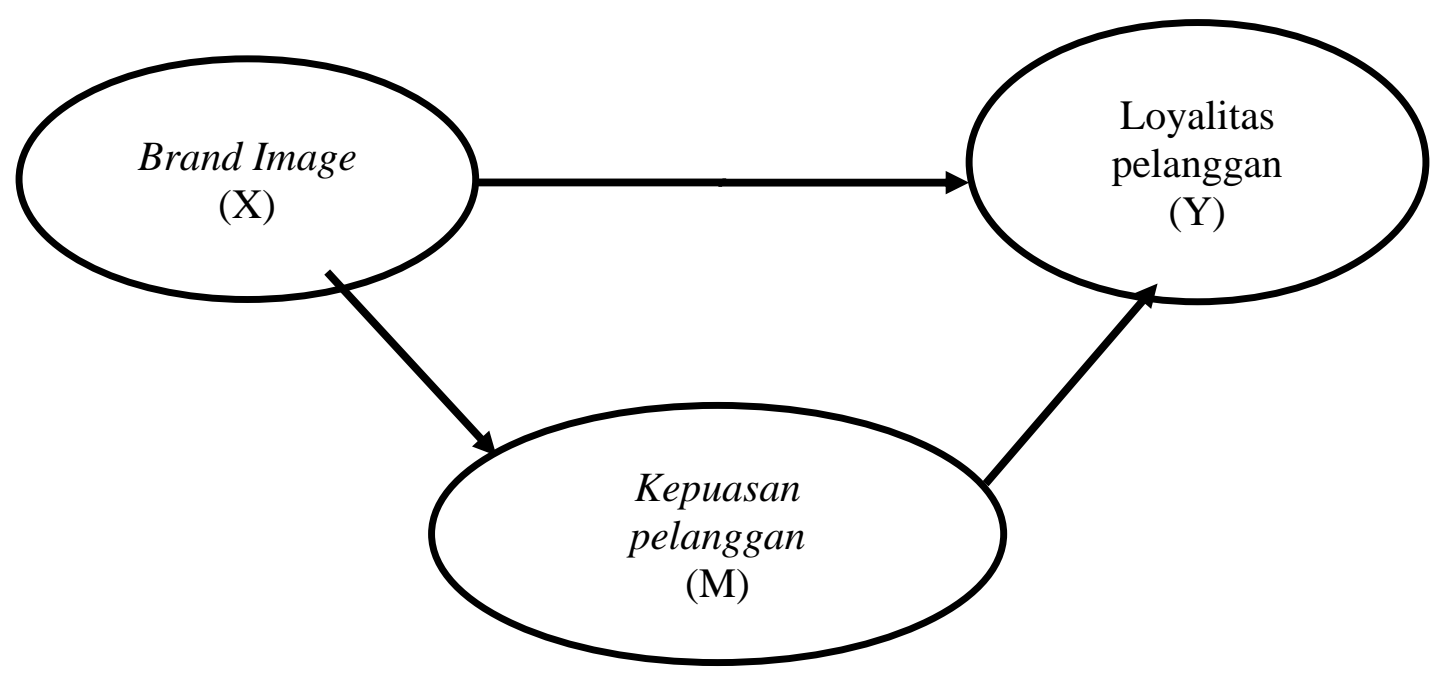

\section{METODOLOGI}

Populasi dan Metode Pengambilan Sampel. Populasi dalam penelitian ini adalah orang yang pernah membeli kasur Lady Americana di Jakarta. Ukuran sampel yang digunakan dalam penelitian ini adalah 135 orang. Metode pengambilan sampel yang digunakan adalah nonprobability sampling. Teknik pengambilan sampel yang digunakan adalah convenience sampling. Berdasarkan data yang terkumpul, mayoritas karakteristik responden pada penelitian ini adalah wanita $(53.7 \%)$, berusia $20-30$ tahun $(48,1 \%)$ dengan pendidikan terakhir mayoritas adalah S1 (55,6\%) yang berpenghasilan rata-rata Rp 2.000.000-9.900.000 (65,9\%).

Variabel dan Pengukuran. Pada penelitian ini, variabel brand image merupakan variabel independen, sedangkan loyalitas pelanggan adalah variabel dependen dengan kepuasan pelanggan sebagai variabel mediator. Untuk mengukur variabel ini, menggunakan beberapa instrument yang diadaptasi dari studi penelitian terdahulu. 
Tabel ini dibawah ini menunjukan pengukuran masing - masing variabel dan sumbernya:

Tabel 1

Variabel dan Pengukuran

\begin{tabular}{|c|c|c|}
\hline VARIABEL & ITEM & SUMBER \\
\hline \multicolumn{3}{|c|}{ Variabel Independent } \\
\hline Brand Image & 6 & Khan et al. (2015) \\
\hline \multicolumn{3}{|c|}{ Variabel Mediator } \\
\hline Kepuasan Pelanggan & 4 & Sheng dan Liu (2010) \\
\hline \multicolumn{3}{|c|}{ Variabel Dependent } \\
\hline Loyalitas Pelanggan & 5 & $\begin{array}{ll}\text { Ndubisi }(2007) ; & \text { Sheng } \\
\text { dan Liu (2010); } & \text { Izogo } \\
(2017) & \end{array}$ \\
\hline
\end{tabular}

Metode Analisis Data. Metode analisis data yang digunakan adalah analisis regresi sederhana. Sedangkan, untuk uji asumsi seperti uji normalitas dan uji heteroskedastisitas saja sedangkan untuk uji multikolinieritas tidak dilakukan karena variabel dalam penelitian ini hanya 1 serta untuk uji otokorelasi juga tidak dilakukan karena data yang digunakan bersifat cross-sectional dan bukan berbasis waktu (time-series), hasilnya menunjukan uji asumsi sudah terpenuhi. Untuk analisis mediasi dalam penelitian ini menggunakan tiga analisis regresi menurut Baron \& Kenny (1986). Pengujian dalam penelitian ini menggunakan program SPSS. Taraf signifikansi yang digunakan dalam penelitian ini adalah 0,05 .

Pengujian untuk analisis data dilakukan dengan pembagian menjadi 4 model yaitu model 1 untuk menguji hipotesis pertama yaitu pengaruh brand image terhadap loyalitas pelanggan, model 2 untuk menguji hipotesis kedua yaitu untuk pengaruh brand image terhadap kepuasan pelanggan, model 3 untuk menguji hipotesis ketiga yaitu pengaruh kepuasan pelanggan terhadap loyalitas pelanggan dan model 4 digunakan untuk menguji hipotesis keempat yaitu untuk menguji peran kepuasan pelanggan dalam memediasi pengaruh brand image terhadap loyalitas pelanggan.

\section{ANALISA DAN PEMBAHASAN}

Tabel 2

Hasil Pengujian Hipotesis

\begin{tabular}{|c|c|c|c|}
\hline Hipotesis & B & Sig & Kesimpulan \\
\hline $\begin{array}{l}\text { Terdapat pengaruh positif antara brand } \\
\text { image terhadap loyalitas pelanggan. }\end{array}$ & 0,545 & 0,000 & Tidak ditolak \\
\hline $\begin{array}{l}\text { Terdapat pengaruh positif antara brand } \\
\text { image terhadap kepuasan pelanggan. }\end{array}$ & 0,406 & 0,000 & Tidak ditolak \\
\hline $\begin{array}{l}\text { Terdapat pengaruh positif antara kepuasan } \\
\text { pelanggan terhadap loyalitas pelanggan. }\end{array}$ & 1,117 & 0,000 & Tidak ditolak \\
\hline \multicolumn{2}{|l|}{ Hipotesis } & $\mathbf{t}$ & Hasil \\
\hline \multicolumn{2}{|c|}{$\begin{array}{l}\text { Kepuasan pelanggan memediasi pengaruh brand image } \\
\text { secara positif terhadap loyalitas pelanggan }\end{array}$} & 8,72 & Tidak ditolak \\
\hline
\end{tabular}


Berdasarkan hasil pengujian hipotesis pada model 1, maka dapat disimpulkan bahwa brand image berpengaruh positif terhadap loyalitas pelanggan. Hipotesis $\mathrm{H} 1$ ini sesuai dengan penelitian Upamanyu dan Sankpal (2011) menunjukkan ada hubungan yang kuat antara brand image dan niat loyalitas merek kosmetik (fair lovely) di Gwalior M.P di India.

Hipotesis kedua (model 2) digunakan untuk menguji apakah brand image berpengaruh positif terhadap kepuasan pelanggan. Berdasarkan hasil rekapitulasi hipotesis diatas juga diketahui bahwa hipotesis kedua terbukti bahwa brand image berpengaruh positif terhadap kepuasan pelanggan. Hipotesis $\mathrm{H} 2$ sudah sesuai dengan penelitian Stan, Caemmere dan Jallet (2013) menyatakan bahwa terdapat pengaruh dari brand image terhadap customer satisfaction.

Hipotesis ketiga (H3) adalah untuk menguji apakah kepuasan pelanggan berpengaruh positif terhadap loyalitas pelanggan. Hasil pengujian hipotesis pada tabel 2 menunjukan pada penelitian ini menemukan bahwa kepuasan pelanggan berpengaruh signifikan pada loyalitas pelanggan. Hasil ini sejalan dengan penelitian Gronholdt, Martensen, dan Kristensen (2000) melakukan penelitian tentang pengaruh kepuasan terhadap loyalitas pelanggan dengan dilihat dari beberapa industri suatu produk.

Hipotesis keempat (H4) menguji apakah kepuasan pelanggan dapat memediasi brand image terhadap loyalitas pelanggan. Hasil pengujian dilakukan dengan menggunakan path analysis menunjukan bahwa pada penelitian ini, kepuasan pelanggan memediasi brand image terhadap loyalitas pelanggan secara positif. Hasil ini sesuai dengan penelitian Andreani (2012) dimana brand image memiki pengaruh yang kuat terhadap customer loyalty lewat variabel mediasi customer satisfaction.

Berdasarkan hasil diatas, maka seluruh hipotesis penelitian ini terbukti dengan adanya data secara empiris. Loyalitas pelanggan dapat diprediksi oleh brand image serta dapat dimediasi oleh kepuasan pelanggan. Dengan demikian, maka dapat dilihat bahwa Loyalitas pelanggan dapat dipengaruhi oleh brand yang dibangun secara konsisten maka pelanggan akan meras puas dengan memakai produk dan akan melakukan keputusan untuk melakukan pembelian ulang.

\section{PENUTUP}

Kesimpulan. Persaingan bisnis yang sangat ketat sekarang ini, para pelaku bisnis harus berkompetisi untuk menciptakan dan mempertahankan loyalitas pelanggan. Keberhasilan suatu bisnis tidak dapat dipisahkan dari pelanggan yang menjadi target utama dari sumber pendapatan bagi perusahaan dan kelangsungan hidup perusahaan. Salah satu faktor penting dalam mewujudkannya adalah menjaga pelanggan agar loyal untuk melakukan pembelian terus menerus adalah dengan kekuatan brand. Pelanggan akan merasa puas apabila produk yang dibelinya merupakan brand yang terkenal dan disukai banyak orang dan pelanggan yang puas tersebut berpotensi untuk melakukan pembelian berulang dan menjadi pelanggan yang loyal.

Dalam penelitian ini menemukan bahwa semakin tinggi brand image maka semakin kuat mempengaruhi kepuasan dan loyalitas pelangan pada Lady Americana di Jakarta. Apabila pelanggan memperoleh sesuai yang diharapkan, maka akan menimbulkan kepuasan pelanggan yang kemudian akan mendorong loyalitas pelanggan makin tinggi.

Saran. Peneliti menyarankan agar Lady Americana di Jakarta melakukan mapping di seluruh area Jakarta. Wilayah Jakarta bagian mana yang paling lemah dalam melakukan promosi dan orang mengenal brand Lady Americana atau mengenal tetapi belum pernah membeli kasur Lady Americana. Branding dapat dilakukan dengan cara melalui media offline dan online. Untuk media offline perusahaan dapat memasang shop sign, billboard, backdrop, roll banner, dan melakukan exhibition di mall - mall premium dengan tujuan untuk meningkatkan brand image di benak konsumen, untuk media online seperti sosial media dan web, Perusahaan dapat memberikan edukasi tentang kualitas tidur yang baik secara berkala dan melakukan 
komunikasi dua arah dengan cepat. Dengan meningkatnya brand image Lady Americana di Jakarta maka pelanggan yang telah membeli kasur Lady Americana merasa percaya dan semakin puas sehingga berpotensi menciptakan pelanggan untuk mengambil keputusan untuk membeli kembali kasur Lady Americana dan memutuskan menjadi pelanggan yang loyal.

\section{DAFTAR PUSTAKA}

Ghafoor, Iqbal dan Murtaza (2012). "Impact of customer satisfaction and brand image on brand loyalty". Progress in business innovation \& Technology Motivation 002 (2012) 069-077

Kotler, P., \& Keller, L. (2015). Marketing Management $15^{\text {th }}$ edition. New Jersey : Pretince Hall.

Kotler, Philip dan Keller, K.L. (2012). Marketing Management. 14 Edition. Harlow : Pearson Education Limited

Upamannyu dan Sankpal. "Effect of brand image on customer satisfaction \& loyalty intention and the role of customer satisfaction between brand image and loyalty intention." Journal of Social Science Research, Vol.3, No.2 (ISSN : 2321 - 1098)

Upamannyu, Mathur dan Gulati (2014). "Effect of brand trus, brand image on customer brand loyalty in FMCG sector at Gwalior Region.” Prestige Institute of Management, April 2014 (ISSN 2319-5789) 